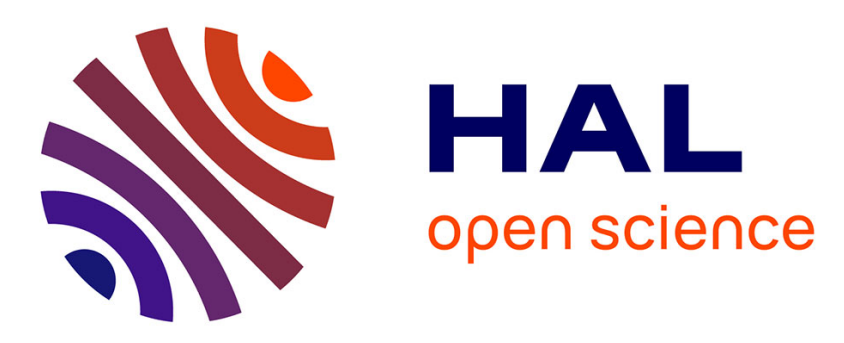

\title{
Thermodynamic assessment of the variation of the surface areas of two synthetic swelling clays during adsorption of water
}

Sébastien Lantenois, Y. Nedellec, Bénédicte Prélot, J. Zajac, Fabrice Muller, J.M. Douillard

\section{To cite this version:}

Sébastien Lantenois, Y. Nedellec, Bénédicte Prélot, J. Zajac, Fabrice Muller, et al.. Thermodynamic assessment of the variation of the surface areas of two synthetic swelling clays during adsorption of water. Journal of Colloid and Interface Science, 2007, 316 (2), pp.1003-1011. 10.1016/j.jcis.2007.07.024 . insu-00192533

\section{HAL Id: insu-00192533 \\ https://hal-insu.archives-ouvertes.fr/insu-00192533}

Submitted on 28 Nov 2007

HAL is a multi-disciplinary open access archive for the deposit and dissemination of scientific research documents, whether they are published or not. The documents may come from teaching and research institutions in France or abroad, or from public or private research centers.
L'archive ouverte pluridisciplinaire HAL, est destinée au dépôt et à la diffusion de documents scientifiques de niveau recherche, publiés ou non, émanant des établissements d'enseignement et de recherche français ou étrangers, des laboratoires publics ou privés. 


\title{
Thermodynamic assessment of the variation of the surface areas of two synthetic swelling clays during adsorption of water
}

\author{
S. Lantenois ${ }^{a}$, Y. Nedellec ${ }^{a}$, B. Prélot ${ }^{a}$, J. Zajac ${ }^{a}$, F. Muller ${ }^{b}$ and J.-M. Douillard ${ }^{a}$ \\ ${ }^{a}$ Institut Charles Gerhardt, AIME (Agrégats, Interfaces et Matériaux pour l'Energie), CNRS, \\ Université Montpellier 2, UMR 5253, CC 015, Place Eugène Bataillon, 34095 Montpellier \\ Cedex 5, France \\ ${ }^{\mathrm{b}}$ Institut des Sciences de la Terre d'Orléans (ISTO), CNRS, Université d'Orléans, 1A rue de la \\ Férollerie, 45071 Orléans Cedex 2, France
}

\begin{abstract}
Two synthetic smectites (montmorillonite and beidellite) are studied by a water adsorption technique in order to assess their specific surface areas under atmospheric conditions. A route recently proposed for extracting the thermodynamic data from experimental adsorption isotherms is used. The variation of the specific surface area during water adsorption is obtained, which can be linked to the enlargement of the interlayer space determined using Xray diffraction. This variation is compared to an idealized specific surface area obtained from TEM and X-ray measurements in agreement with crystallographic models. All these results are also compared with those obtained previously for a natural montmorillonite. A simple view of swelling is proposed.
\end{abstract}

\section{Graphical abstract}

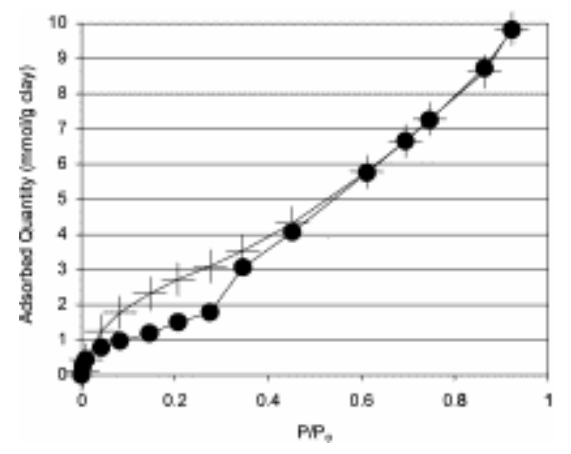

Keywords: Montmorillonite; Beidellite; Synthetic smectite; Water; Adsorption; Surface area; Swelling clay; Interlayer space 


\section{Introduction}

Synthetic clays are very interesting materials, both for scientific research and for industrial applications. Indeed, with natural solids, the great variability of chemical composition, crystallographic characteristics, and shape or dimensions of particles is a problem, when looking at fine interpretation of results or reproducibility of processes. This is due to the complexity of purification processes and to the very simple fact that natural clays are extracted from deposits whose structure is obviously not uniform [1]. However, synthetic samples are reproducible and homogeneous and thus are useful for systematic studies. Some parameters such as the charge location inside the layer structure can be controlled. One of us has recently studied synthetic beidellite and montmorillonite samples [2] and [3], which are swelling clays [4]. Resulting samples have been structurally and chemically characterized using X-ray diffraction, IR spectroscopy, thermal analysis, NMR, electron microprobes, TEM, and measurements of the CEC. The point is that these synthetic clays are very representative of their clay families and are quite easy to produce. Montmorillonite and beidellite differ in the location of the deficit of charge in the structure.

In this paper, we perform a surface characterization of these samples, using both nitrogen and water adsorption isotherms, in order to assess the specific surface area under ambient conditions and to interpret the variations of this physical parameter.

However, this assessment is a point still in debate in the literature [5]. Indeed, it is well known that the determination of the specific surface area of swelling products is quite difficult. This is due to a simple reason. The simplest technique of determination of specific surface area uses the measurement of adsorption isotherms of gas or vapor in combination with thermodynamic analysis [6]. However, what is generally determined under the name of "adsorption isotherms" is determined using experimental routines, which are only correct when the surface area is constant all over the experimental time [7]. This is obviously not the case for swelling solids.

To solve this problem, one of us has proposed a route to analysis of the experimental curves, so-called isotherms, giving access to correct thermodynamic adsorption isotherms [8]. This approach has recently been reviewed [5] and routinely used to compare cation substitutions of a natural clay [9].

We use this route here and we also propose some simplifications in order to give access to a simple routine to analyze swelling adsorption isotherms. Therefore, it is possible to derive the variations of the surface area vs the adsorbed quantity of the molecule, which induces the swelling of the clay.

The surface area variation is thus explained by the actual accessibility of the clay layers to water, which is only partial, even at high partial pressure. The quantitative behaviors appear to be linked to the location of the charge, although the qualitative behaviors are not greatly different. 


\section{Experimental background}

\subsection{Synthetic samples}

Synthetic clays were crystallized from gels under hydrothermal conditions. Gels were prepared following the usual method adapted from Hamilton and Henderson [10] and using tetraethylorthosilicate (TEOS), $\mathrm{Mg}\left(\mathrm{NO}_{3}\right)_{2} \cdot 6 \mathrm{H}_{2} \mathrm{O}, \mathrm{Al}\left(\mathrm{NO}_{3}\right)_{3} \cdot 9 \mathrm{H}_{2} \mathrm{O}, \mathrm{HNO}_{3}, \mathrm{NaCO}_{3}, \mathrm{NH}_{4} \mathrm{OH}$, and ethanol. All reagents had a 99\% minimum grade. After dissolution of $\mathrm{Al}$ and $\mathrm{Mg}$ nitrates and of $\mathrm{NaCO}_{3}$ in nitric acid, TEOS and ethanol were added. A precipitate was obtained by neutralizing the resulting solution at $\mathrm{pH} \approx 6$ with addition of $\mathrm{NH}_{4} \mathrm{OH}$. This precipitate was dried at $353 \mathrm{~K}$ for $24 \mathrm{~h}$, ground in an agate mortar, and heated to $673 \mathrm{~K}$ to remove nitrates and carbonates and to obtain a gel composed essentially of $\mathrm{Al}, \mathrm{Mg}, \mathrm{Si}$, and $\mathrm{Na}$ oxides. $\mathrm{SM}_{0.33^{-}}$ 1200 montmorillonite was synthesized from such gels in an internally heated pressure vessel. Gel and deionized water were introduced in a 1:2 weight ratio into a gold tube itself sealed and placed in a vessel heated at $623 \mathrm{~K}$ for 30 days at a fixed pressure of $120 \mathrm{MPa}$ [2]. The SB1-350 beidellite was synthesized in an internally heated pressure vessel. A quantity of 600 mg of gel was mixed with $1.3 \mathrm{~g}$ of a $\mathrm{NaOH}$ solution $(0.2 \mathrm{~N})$ in a gold tube. The tube was then sealed and heated to $623 \mathrm{~K}$ under $22 \mathrm{MPa}$ for 15 days [3]. After cooling of the vessels, the solid products were extracted from the reaction tubes, washed by filtration using deionized water, dried at $353 \mathrm{~K}$ overnight, and ground. Structural and chemical characterization using elementary analysis, X-ray diffraction, infrared spectroscopy, cation exchange capacity, and an electron microprobe analyzer (EMPA) has been performed [2] and [3]. Chemical formulae obtained from chemical analysis are summarized in Table 1.

\subsection{Adsorption of nitrogen at $77 \mathrm{~K}$}

The adsorption of nitrogen at $77 \mathrm{~K}$ was performed using a Micromeritics ASAP 2010 apparatus. Before the experiment, each sample was outgassed $5 \mathrm{~h}$ at $323 \mathrm{~K}$, under a vacuum lower than $10^{-3}$ Torr.

\subsection{Adsorption of water vapor at $298 \mathrm{~K}$}

The vapor adsorption isotherms of water at ambient temperature were performed with a homemade adsorption device (denoted MAB) [11] designed around the gravimetric technique. The main points are the following. The outgassing of the sample (at a temperature of $473 \mathrm{~K}$ for $24 \mathrm{~h}$ ) under very low pressure $\left(10^{-6}\right.$ Torr) is obtained using a Varian vacuum system (dynamic vacuum is lower than $10^{-6}$ Torr); the introduction of the vapor is regulated by an automatic point-by-point procedure; the pressure measurement is regulated by four gauges acting at different levels of pressure $\left(10^{-4}-0.1 ; 10^{-3}-1 ; 10^{-2}-10 ; 1-1000\right.$ Torr $)$ with, in each case, a precision of $0.05 \%$ (equipment was supplied by MKS, Baratron, France); a Sartorius vacuum microbalance measures the variation of the sample weight with a precision of 0.01 $\mu \mathrm{g}$; the temperature of the different parts of the MAB (microbalance, gauges, reference volume, and the device devoted to the vapor introduction) is controlled with a precision of $0.05^{\circ} \mathrm{C}$. Some other details are given elsewhere [11]. 


\subsection{X-ray diffraction}

X-ray diffraction patterns were recorded using a Thermo Electron ARL'XTRA diffractometer equipped with a $\mathrm{Si}(\mathrm{Li})$ solid detector. The vertical $\underline{\theta: \theta}$ goniometer supports two Sollers slits. A VTI RH 200 relative humidity generator device coupled to an Anton Paar HTK 1200R chamber makes it possible to have variable environmental conditions. Experimental measurement parameters were $10 \mathrm{~s}$ counting time per $0.05^{\circ} 2 \theta$ step. The divergence slit, the incident beam scatter slit, the diffracted beam scatter slit, and the receiving slit are 1.0, 1.5, 0.45 , and $0.30 \mathrm{~mm}$, respectively. Between 30 and $60 \mathrm{mg}$ of powder sample are necessary for XRD analysis. Data collection was performed at different relative humidity steps. The first step, at 5\% relative humidity $(\mathrm{RH})$ was obtained after an equilibrium period of $15 \mathrm{~h}$ before measurement. Then the samples were progressively hydrated from 5 to $97 \% \mathrm{HR}$ during a 1-h equilibrium period before the pattern was recorded.

\section{General presentation of montmorillonite and beidellite}

Montmorillonite and beidellite are phyllosilicates, i.e., composed of aluminosilicate layers stacked one above the other, to compose particles with elementary layers more or less ordered along the $c$-axis. Layers are mainly composed of silicon, oxygen, aluminum, and magnesium [4]. In such structures, there is partial substitution of Al or Si atoms, creating a loss of electrical charges, in other words, a negative charge, which is compensated for by some cations, which are located in the interlayer space. These cations are generally $\mathrm{Na}^{+}$and $\mathrm{Ca}^{2+}$.

Montmorillonite and beidellite are smectites; i.e., they swell in the presence of water. The interlayer space can thus vary between 1 and $2 \mathrm{~nm}$ (and more, in gels for instance), depending on the thermodynamic conditions [4].

The following general chemical formula of montmorillonite is admitted in the literature: $(\mathrm{Na}, 0.5 \mathrm{Ca})_{0.6}(\mathrm{Al}, \mathrm{Mg})_{4} \mathrm{Si}_{8} \mathrm{O}_{20}(\mathrm{OH})_{4} \cdot n \mathrm{H}_{2} \mathrm{O}$, corresponding to substitution of magnesium atoms for aluminum atoms in octahedral sites. The precise crystal structure is still in discussion [12]. The space group is $C 2$. A $\underline{C 2 / m}$ (\#12) symmetry has also been reported. This dual possibility is due to some lacking positions of $\mathrm{Al}$ or $\mathrm{Mg}$ atoms. If $\underline{C 2 / m}$ is used, it is necessary for calculations to use files with some masked atom positions. This is the route followed here for generating the sketch of the cell. The reported cell dimensions are $a=5.17 \pm 0.02 \AA$; $b=8.94 \pm 0.02 A ; c=9.95 \pm 0.06 \AA ; \beta=99^{\circ} 54^{\prime} \pm 30^{\prime}$. The architecture is composed of $\mathrm{SiO}_{4}$ tetrahedra and $\mathrm{AlO}_{6}$ octahedra and is very near to the chlorite crystal structure. The structure of a basic cell is reported in Fig. 1 for the Na form.

Beidellite is not very different from montmorillonites. However, the charge deficit is essentially localized in tetrahedral sheets by substitutions of aluminum for silicon. Therefore, the $C 2 / m$ symmetry is necessary to describe the structure. Reported cell dimensions are

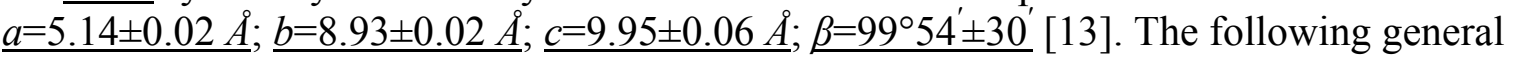
chemical formula is admitted in the literature: $(\mathrm{Na})(\mathrm{Al})_{4}\left(\mathrm{Si}_{7} \mathrm{Al}\right) \mathrm{O}_{20}(\mathrm{OH})_{4} n \mathrm{H}_{2} \mathrm{O}$. The structure of a basic cell is reported in Fig. 2 for the $\mathrm{Na}$ form. 


\section{Thermodynamical background}

\subsection{Standard isotherms}

The adsorption isotherm describing the variation of an adsorbed vapor quantity vs the chemical potential of the vapor can be simply derived [14] from the definition of the surface free energy $\underline{G^{S}}$ of an interface between two phases, solid and vapor, containing $i$ chemical species.

The definition of the total surface free energy is

$$
G^{s}=\sum_{i} n \mu_{i}+A \gamma
$$

When the chemical potential $\underline{\mu}_{i}$ of the gas phase changes with $\underline{P / P_{0}}$ (where $\underline{P}_{0}$ is the saturation pressure of the gas), for a defined surface area of contact (i.e., the surface area taken as constant), one has the definition of the surface excess of a species $I$,

$$
\Gamma_{i}=\left(\frac{\partial \gamma}{\partial \mu_{i}}\right)_{A}
$$

Looking at a solid-vapor interface, it is obvious that the experimental surface area depends directly on the quantity of solid phase involved in the process. Generally, the experiments are performed knowing the mass of the solid phase [6] and [14]. Therefore, the experimental surface area is the product of the specific surface area of the solid and the mass used in the experiment. This link allows the experimental calculation of the specific surface area of the solid to be made.

Therefore, for the sake of simplicity, the adsorption isotherms generally represented are the variation of the adsorbed quantity expressed per gram of solid vs the partial pressure of the gas (according to the IUPAC classification [15], for instance). This representation is in fairly good agreement with a more correct (from the thermodynamic viewpoint) adsorption isotherm, which is the variation of the adsorbed quantity per unit surface area vs the log of the partial pressure of the gas (see Eq. (2)).

However, one can have a strong discrepancy between the usual representation and the variation of the thermodynamical surface excess when the surface area developed by the solid phase is not constant during the process, which is obviously the case for swelling systems (swelling clays, polymers). It is then necessary to interpret the experimental isotherm to get the correct thermodynamic adsorption isotherm corresponding to Eq. (2), i.e., a derivative of the free energy at constant surface area.

In the case of swelling solids, where a solid surface area is always present during the process (which is not the case for dissolution problems, for example), this is possible by using standard isotherms [16], which are very representative of the experimental variations, when no porosity takes place. The understanding of the quality of the fit of standard isotherms can 
now be described as follows. It is currently clear that the adsorption of vapor molecules onto actual solids is the result of the sum of a great number of various chemical reactions (of low energy), which are similar in nature (i.e., interaction between the adsorbed vapor and the sites of the solid) but different in the details of the interactions involved. This is due to many things such as the roughness of the solid surface and the presence of edges, cracks, and other physical and chemical defects [17]. It is also due to the variability of the environment, both chemical and physical, of species located at equivalent crystallographic positions, etc. This has been demonstrated by Langmuir [18]. When a large sum of slightly different interactions is taken into account, the adsorption isotherms tend to a type II shape (according to IUPAC nomenclature).

Therefore, in actual cases, when strong interactions are attempted between the vapor and the solid sites, a type II is expected. When a macroporosity takes place, the right part of the isotherm can be different and then a type IV is expected. This general behavior has been formalized in agreement with the usual classifications [16] and is known as the result of the "surface heterogeneity" [19] and [20].

Therefore, one expects actual experimental isotherms to follow some simple graphical shapes. Following the ideas presented above, such shapes have to be justified not by chemical reasons, but only by mathematical reasons. One could call these mathematical expressions "mathematical isotherms" or "graphical isotherms" or "ideal isotherms." For historical reasons, they are often called "standard." Unfortunately, they are frequently justified by very subtle chemical arguments, even though this is unnecessary [15].

Some data or equation-defining shapes have been proposed. The most famous standard isotherm, the BET equation, can be obtained by summation of an infinite number of individual curves describing the adsorption of individual layers onto the surface of the solid. Even though it can be obtained in another mathematical way, very simple and straightforward, it is meaningful to consider the BET equation as the limit of a general isotherm equation describing a process where the adsorption is considered as the sum of homogeneous layers adsorbing successively onto the surface: a multilayer. In this case, the word "homogeneous" need not be understood from a strict chemical point of view. It means simply that the adsorbed molecules of the same "layer" are indistinguishable, and the corresponding energetic parameters are mean values.

It has been demonstrated that the general "multilayer" form is one of the best standard isotherms for looking generally to various solid surfaces [21]. (When looking to certain chemical species, for example, silica, one gets more precise analysis with the use as standards of experimental isotherms obtained with well-calibrated samples [22].)

However, it was not mentioned above, but the extreme right part of the isotherm, which corresponds to liquefaction in macropores or on free surfaces, is not correctly described by standard isotherms, because another physical process (i.e., liquefaction) takes place. Therefore, the quality of the fit between a standard isotherm and data has to be judged only below a partial pressure of 0.85 .

In these limits, it is very easy and fruitful to compare experimental isotherms to a multilayer isotherm. The experimental isotherm has to be considered as the product of a standard isotherm by a scale factor linked to the surface area 
We will use here the following Lecloux-Pirard form, which is very efficient,

$$
n=n_{m}\left[\frac{x\left(1-(N+1) x^{N}+N x^{N+1}\right)}{(1-x)\left(\frac{1}{C}+\left(\frac{C-1}{C}\right) x-x^{N+1}\right)}\right],
$$

where $x$ is $\underline{P / P_{0}}, n$ is the adsorbed quantity related to a unit mass of solid, $N$ is the number of adsorbing layers, and $C$ is the BET constant. The scale factor of such a fit is $\underline{n}_{m}$, the number of molecules adsorbed at the first curvature mean change of the isotherm, which is called "point B" and is generally considered to be the location of the achievement of the monolayer, even though this idea is hard to demonstrate. The number $N$ is not to be considered strictly as a real number of layers. Indeed, in the equation, this parameter indicates a certain curvature of the isotherm at the end of the process. This means it is related to a derivative of the energy. It then can be compared to the $C$ constant; i.e., it is an enthalpic parameter, which reflects the strength of the interactions, even though the interactions are different in the right part and in the left part of the isotherm.

Using these ideas, it is then possible to determine specific surface areas of solids using either a graphical interpretation, the BET procedure, or a determination of the scale factor using the fit of a multilayer isotherm: this is strictly speaking the same route. However, as claimed by IUPAC [15], it is better to use the BET linearization, in order to get better precision.

The point is that an experimental isotherm can be simply described by a standard isotherm equation multiplied by a scale factor, which is the number of molecules at point $\mathrm{B}$. An example is given in Fig. 3, where the experimental $\mathrm{N}_{2}$ adsorption isotherm on the synthetic beidellite of our study is well fitted for partial pressures going from 0.05 to 0.85 by a Lecloux-Pirard isotherm.

\subsection{Case of swelling solids}

Of course, when swelling solids are studied, the specific surface area is not constant during the experiment, which is not in accordance with Eq. (2). However, the quantity adsorbed per unit mass of solid has still a physical sense. And each adsorbed amount at equilibrium corresponds to a given value of specific surface area, meaning that Eq. (2) is correct to describe each point but not the entire set of data using the same parameters. Therefore, we have proposed to consider the experimental adsorption isotherm determined for swelling solids as composed of successive adsorption isotherms at various constant surface areas. The basic route is as follows. We adjust the left part of the isotherm using the BET transform procedure, assuming and verifying that the surface area does not vary between $\underline{P / P_{0}} 0.05$ and 0.2 , which are the limiting values of the BET analysis (this is a necessary condition of the application of the routine). We compare the obtained "monolayer value" to the total amount adsorbed and we calculate the number of layers at the end of the process and set $N$ as this value. Then, using this value and the BET parameters in the Lecloux-Pirard equation, we establish a master curve. It is then possible to divide the experimental isotherm by the master curve and to get directly the surface area through the variation of $\underline{n}_{m}$ vs $\underline{P / P_{0}}$.

Therefore, we assume that this isotherm master curve should be the correct description of the process for any pressure. Physically, this means that we consider that the same chemical reactions are the cause of the adsorption for any pressure. Then the experimental isotherm is 
simply a set of identical multilayer isotherms multiplied by scale factors varying all along the pressure. In other words, we consider that the specific surface area varies all along the process, which is expected from knowledge of clay physics.

Two scaled isotherms are drawn in Fig. 4 in order to fit the experimental isotherm of water (i.e., swelling conditions) determined for the synthetic beidellite described above. The point is that great parts of the experimental isotherm are well described by only two scaled isotherms. This confirms that the surface area of smectites varies by steps. Such a variation is reported in Fig. 5. This was expected and is a proof of the quality of the model.

It has to be pointed out that another procedure is possible and was originally proposed. It is possible to assess the final number of adsorbed layers using thermal analysis, for example, a gravimetric analysis of the drying of the sample. Indeed, it is well known that the behavior of the first adsorbing layer and the following ones is very energetically different. Therefore, a change of slope of the weight change during drying is easy to see on the thermal analysis curve. This change of slope can be used to assess the quantity adsorbed as the first layer and the total quantity. Thus, it is easy to determine the number of adsorbed layers. However, experimental data from our laboratory and from co-workers [23], concerning a great number of montmorillonites, show that such an analysis does not give different results from the ones determined through adsorption isotherms (final adsorption compared to the monolayer value), if the experimental determination of the isotherm is of good quality. Therefore, it is not necessary to use such data. Thus, the alternative route proposed here is better because it is very simple.

\section{Results}

\subsection{Determination of the specific surface area}

The experimental adsorption isotherms of water onto montmorillonite are reported in Fig. 6. The corresponding specific surface areas deduced from these data are reported in Fig. 7. The set of data, including the $\mathrm{N}_{2}$-BET surface area, is reported in Table 2, where results obtained with a natural montmorillonite described elsewhere are also reported. This natural montmorillonite was previously analyzed and reported in Ref. [8] with our more refined routine. The low specific surface area obtained for the natural montmorillonite is related to the heterogeneity of the sample and to the greater size of the particles obtained after the same grinding as synthetic samples.

Here, we have used the simplified routine (according to the discussion above) in order to give a meaningful comparison. We report only two values for the sake of simplicity and comparison: the specific surface area around a partial pressure of 0.1 and the specific surface area around a partial pressure of 0.8 .

\section{2. $X$-ray data}

We report in Fig. 8 the variation of the basal distance observed for the two synthetic smectites. It is clear that the increase of this distance from the dry situation (about $10 \AA$ ) begins at low pressure. This implies that data issued from adsorption of water and use of standard isotherms correspond to samples containing particles presenting basal distances of 12.25 $\AA$, which is not the case for the BET surface areas obtained through $\mathrm{N}_{2}$ adsorption measurements at $77 \mathrm{~K}$. The small differences between BET surface areas and surface areas 
under low pressure of water, in the case of synthetic smectites, show that at low pressure of water, the opening of layers is too small to allow the adsorption of water inside the interlayer space to be realized. The low difference with nitrogen adsorption indicates also a small influence of the surface area due to the edges (surface area generated by the first opening at $12.25 \AA$ ). The natural montmorillonite from Mostaganem shows a lower surface area with $\mathrm{N}_{2}$ adsorption. The particles are agglomerates, which open under a low water pressure, as discussed in Refs. [8] and [9].

Some other information can be derived from X-ray data. Using the Scherrer formula [24], it is possible to deduce that for montmorillonite, the number of sheets composing a particle (i.e., the thickness along axis $c$ ) varies from 9 to 7 when the basal distance increases to $15 \AA$. This number of layers is smaller for the beidellite, going from 8 to 6 .

The trend has to be pointed out that the particles are smaller when the thickness of the interlayer increases. This is generally observed [25] and is probably due to a decrease of the mechanical coherency of the particles, linked to the forces acting in the interlayer.

The second increase (from 12.25 to 15 ) begins at 0.45 for montmorillonite and at 0.6 for beidellite. This is related to the location of the substitution inside the crystal. The force ensuring the cohesion between the layers is stronger in the case of the beidellite. Indeed, the location of the charge is nearer to the surface of the layer and thus can have a stronger influence on interactions through the interlayer space.

\subsection{Discussion}

The first observation derived from experiments (Table 2) is the great difference between the specific surface areas obtained both at the beginning and at the end of the adsorption from the specific surface areas expected for swollen materials. Indeed, many experimental results obtained with the help of adsorption of polar molecules ensuring complete swelling show that the specific surface area of swollen clays is about $800 \mathrm{~m}^{2} / \mathrm{g}$ [26]. This value is in good agreement with that obtained through considerations of crystal dimensions. Indeed, it is possible to estimate the specific surface area of an idealized perfect layer, i.e., of a totally swollen sample. Assuming that the thickness of this perfect layer is negligible (i.e., taking only into account the basal surfaces, i.e., along axes $a$ and $b$ ), we get for a montmorillonite of the formula $\mathrm{Na}\left(\mathrm{Al}_{3} \mathrm{Mg}\right)(\mathrm{Si})_{8} \mathrm{O}_{20}(\mathrm{OH})_{4}$ a specific surface area $\underline{A}_{S}$ of $756.8 \mathrm{~m}^{2} / \mathrm{g}$. For a beidellite of formula $\mathrm{Na}(\mathrm{Al})_{4}\left(\mathrm{Si}_{7} \mathrm{Al}\right) \mathrm{O}_{20}(\mathrm{OH})_{4}$, we get a value of $751.2 \mathrm{~m}^{2} / \mathrm{g}$. Some data from the literature [27] indicate that the surface area of swollen natural beidellites $\left(597 \mathrm{~m}^{2} / \mathrm{g}\right)$ is lower than the surface area of swollen montmorillonites (about $812 \mathrm{~m}^{2} / \mathrm{g}$ ). However, it is difficult to consider these experimental data as a general case. They could be due to the chemical differences between the two crystals inducing differences of mechanical stability of the isolated unit cells. But this difference could also be due to practical reasons (the shape and dimensions of the particles, which depend on the history of the sample and which can vary with the nature of the sample).

Otherwise, it can be noted that the part due to the edges is not important in the experimental data linked to total swelling, which correspond mainly to the above estimate of the basal surfaces alone. This is confirmed by some works focusing on the shape of particles [28].

The point here is that the total basal surface area of each layer is greater than the one determined here through water adsorption. This is due to the packing of layers, implying that 
a part of the basal surface is in fact an interlayer surface, which does not adsorb following the same behavior. Indeed, it is always observed that particles are composed of sandwiches of individual layers. Microscopy and present X-ray data are in agreement with stacking along axis $c$ of individual layers developed along the $a b$ axes. This composes tabular particles, with a thickness which can go from a monolayer (a very rare case) to 30-35 layers [29]. The particles of saponite (another swelling clay) described by Michot and Villiéras [28] (a length of $250 \mathrm{~nm}$ for a thickness of $25.7 \mathrm{~nm}$ ) are also in agreement with this picture and present a basal/total surface ratio of $86 / 14$.

The surface areas developed by the particles described by Michot and Villiéras are lower than the data determined in this work. Thus it is possible to consider that our data correspond to smaller particles, which could be idealized as tabular particles with a length of about $68 \mathrm{~nm}$ $(\underline{a}=5.17 \AA A, \underline{b=8.94 A}$, i.e., a development of 100 unit cells along axes $a$ and $b$ ) with a thickness of $11.02 \mathrm{~nm}$, corresponding to the stacking of nine layers around $\underline{P / P_{0}=0.2}$. This estimate is in agreement with TEM data (Fig. 9) derived from Ref. [2] and gives a total surface area of $111.6 \mathrm{~m}^{2} / \mathrm{g}$, in agreement with the trend of our adsorption results (with a density of

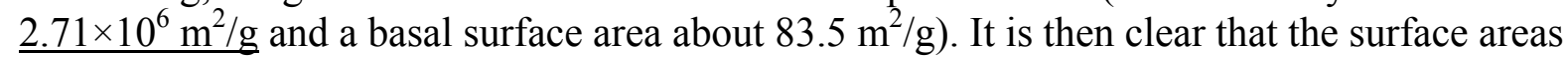
determined here are in agreement with the known microstructure of clay particles at low partial pressure and before swelling. However, the low increase of surface area with swelling remains to be explained.

Indeed, there is a great difference between the actual adsorbed quantities and the calculated adsorbed quantities, which could be expected on such "opened" particles. It is often assumed that the increase of the interlayer distance corresponds to the intercalation of water molecules in the interlayer space. However, if the interlayer space were completely accessible to water molecules, a surface area of $800 \mathrm{~m}^{2} / \mathrm{g}$ should be expected. At the end of the adsorption, a certain number of molecular layers adsorbed onto the external faces should also be obtained, due to the influence of liquefaction forces. This would correspond to a great quantity of water. Such a quantity should correspond - with a reasonable assumption of the adsorption of five layers of water at the end of the process - to about $53 \mathrm{mmol}$ of water per $\mathrm{g}$ of clay, instead of the 12-16 observed here (which are in agreement with the comparable literature data). Of course, the assumption of homogeneous adsorption is the simplest, but it is not realistic, because one has to take into account the cohesion between layers. It would be better to consider the total interlayer volume as occupied by a single or double layer of water molecules, combined with a five-layer adsorption on the external surfaces. Such adsorption can be modeled by particles such as the ones idealized above, i.e., layers developed on axes $a$ and $b$ with a hundred unit cells stacked by 9 along the $c$-axis. At a partial pressure of 0.45 , this tabular structure would develop an external surface of $111 \mathrm{~m}^{2} / \mathrm{g}$ (a value related to the basal distance of $12.25 \AA$ ) with 1.7 layers of water (determined using the Lecloux-Pirard isotherm) and 8 internal faces with one layer of water (the hypothesis called "one-layer hydrate"). This would give rise to quantities of water of $[0.01328 \times(1.7 \times 111.6+892.8)]$, i.e., $14.37 \mathrm{mmol} / \mathrm{g}$ of clay instead of the observed $4.9 \mathrm{mmol}$. This indicate that the interlayer surface area, i.e., the difference between the external geometric value and the total one, is not full, compared to a situation with two monolayers inside the interlayer. For higher partial pressure, say 0.85 , and $15 \AA$ A swelling, one expects smaller particles. Taking into account X-ray data indicating smaller particles, we will assume here a smaller particle composed of 8 stacked layers with the same lengths as preceding along $a$ and $b$. On such a hypothetical particle, one expects 4.15 layers on $118 \mathrm{~m}^{2} / \mathrm{g}$ of external surface. This gives a proportion of $6.5 \mathrm{mmol}$ in the $12.1 \mathrm{mmol}$ experimental value. The difference of $5.6 \mathrm{mmol}$ should correspond to $16.45 \mathrm{mmol}$ for the dihydrate situation, i.e., an occupation of $32 \%$ of the space (see also Table 3 ). 
The various possibilities are sketched in Fig. 10. It is possible to fit the experimental data by using a curve, which is the sum of a Lecloux-Pirard isotherm (also drawn in Fig. 10) taking into account the increase of the interlayer following X-ray data and of a simulation of the intercalation of water inside the interlayer corresponding to successively $25 \%$ of fullness (for $12.25 \AA$ ) and $30 \%$ (dihydrate situation - interlayer space of $15 \AA$ ). Of course, the intercalation of water is a progressive process and it could be easy to fit the experimental data precisely. However, the Lecloux-Pirard fit depends here precisely on two assumed parameters, the final number of layers on the external surface, and the modification of the external surface area according to the size decrease of the particles, which are not precisely known. Therefore, such a precise fit needs not be researched.

One has to conclude that a great part of the interlayer space is empty even at the end of the adsorption, which could explain some problems of agreement of interpretations between adsorption data and suction data [30].

\section{Conclusions}

From our analysis of data, the adsorption can be viewed as follows. For very low vapor pressures $(\underline{0<P / P} 0 \leq 0.05)$, the adsorption takes place mainly on the external faces. The adsorption on edge sites induces an increase of the interlayer space, up to a basal distance of $12.25 \AA$. The solid particles are then mainly composed of layers with a basal distance of 12.25 Å. One goes from one adsorption layer surrounding the particles to two adsorption layers with an increasing quantity of water hydrating the cations inside the interlayer space. This water is probably clustering around interlayer cations, modifies strongly the electrostatic interactions, and allows a supplementary increase of the interlayer distance. However, such organization of water molecules in the interlayer space looks probably more like pillars than like a homogeneous distribution all along the interlayer volume. Indeed, the water quantity represents less than $30 \%$ of the volume available in the interlayer space at the end of each step. Such a picture is in agreement with a recent analysis of swelling of saponites [31], considering that no complete water layer is present in the interlayer region in the case of the so-called "one-layer hydrate." And it can explain the fact that the energies associated with such behaviors are not greatly different from the energies insuring adsorption on the external faces, a point that is deduced from the analysis herein of the successive adsorption isotherms composing the experimental result, which are not very different from what can be observed for silicas, for example. This lack of influence is due to the relatively small number of molecules inside the interlayer space. This low influence can also explain the fact that the charge of the layer does not highly influence the general adsorption behavior. This influence is expected when the two-layer hydrate hypothesis is considered, but is not verified. However, the influence of the nature of the cation, which induces various water clustering behaviors, is expected from our analysis and will be studied using the same route in a near future.

The differences between beidellite and montmorillonite, which have the same behavior of opening of the internal layer (about $15 \AA$ ) but present various values of the partial pressure (i.e., vapor energy) necessary to open the interlayer volume, can be attributed to the location of the charge. The cohesion is greater for the beidellite. This difference in the opening explains the quantitative difference between adsorptions of water onto the two samples. As the opening begins at lower pressure for montmorillonite, the intercalation of water begins at lower pressure and the adsorbed quantity is the sum of the external surface (about the same) and of a greater quantity of internal surface. 
There are few differences of behavior between the natural and the synthetic montmorillonite. This confirms that synthetic samples are good representatives of natural samples and can be used fruitfully to interpret the influence of the various structural and chemical parameters on general behavior of clays. 


\section{References}

[1] W.A. Deer, R.A. Howie and J. Zussman, An Introduction to the Rock-Forming Minerals, Prentice-Hall (1996).

[2] S. Lantenois, R. Champallier, J.-M. Beny, F. Muller, Appl. Clay Sci. (2007), in press.

[3] S. Lantenois, F. Muller, J.-M. Bény, R. Champallier, Clays Clay Miner. (2007), in press.

[4] F. Bergaya, B.K.G. Theng and G. Lagaly, Handbook of Clay Science, Elsevier, Amsterdam (2006).

[5] B.S.J. Prakash In: E.F. Wypych and K.G. Satyanarayana, Editors, Clay Surfaces:

Fundamentals and Applications, Elsevier, Amsterdam (2004), p. 90.

[6] J. Rouquerol, F. Rouquerol and K.S.W. Sing, Adsorption by Powders and Porous Solids: Principles, Methodology and Applications, Academic Press, San Diego (1999).

[7] A.W. Adamson and A.P. Gast, Physical Chemistry of Surfaces (sixth ed.), Wiley, New York (1997).

[8] V. Medout-Marere, H. Belarbi, P. Thomas, F. Morato, J.C. Giuntini and J.M. Douillard, J. Colloid Interface Sci. 202 (1998), p. 139.

[9] A. Haouzi, F. Salles, M. Henry and J.-M. Douillard, J. Colloid Interface Sci. 307 (2007), p. 531.

[10] D.L. Hamilton and C.M.B. Henderson, Mineral. Mag. 36 (1968), p. 832.

[11] R. Sarraf, B. Faucompré, J.M. Douillard and S. Partyka, Langmuir 13 (1997), p. 1274.

[12] J.M. Douillard, F. Salles, S. Devautour-Vinot, A. Manteghetti and M. Henry, J. Colloid Interface Sci. 306 (2007), p. 175.

[13] A.H. Weir and R. Greene-Kelly, Am. Mineral. 47 (1962), p. 137.

[14] R. Defay, I. Prigogine, A. Bellemans and D.H. Everett, Surface Tension and Adsorption, Longmans, Green, London (1966).

[15] J. Rouquerol, D. Avnir, C.W. Fairbridge, D.H. Everett, J.H. Haynes, N. Pernicone, J.D. Ramsay, K.S.W. Sing and K.K. Unger, Pure Appl. Chem. 66 (1994), p. 1739.

[16] S.G. Gregg and G.K.S.W. Sing, Adsorption, Surface Area and Porosity, Academic Press, London (1982).

[17] B. Prélot, F. Villiéras, M. Pelletier, G. Gerard, F. Gaboriaud, J.J. Ehrhardt, J. Perrone, M. Fedoroff, J. Jeanjean, G. Lefevre, L. Mazerolles, J.L. Pastol, J.C. Rouchaud and C. Lindecker, J. Colloid Interface Sci. 261 (2003), p. 244.

[18] I. Langmuir, J. Am. Chem. Soc. 40 (1918), p. 1361. 
[19] W. Rudzinski and D.H. Everett, Adsorption of Gases on Heterogeneous Surfaces, Academic Press, London (1992).

[20] W. Rudzinski, J. Narkiewicz-Michalek, R. Charmas, M. Drach, W. Piasecki and J. Zajac In: N. Kallay, Editor, Interfacial Dynamics, Dekker, New York (1999), p. 83.

[21] A. Lecloux and J.P. Pirard, J. Colloid Interface Sci. 70 (1979), p. 265.

[22] J.D. Carruthers, P.A. Cutting, R.E. Day, M.R. Harris, S.A. Mitchell and K.S.W. Sing, Chem. Ind. (1968), p. 1772.

[23] F. Salles, Physique et Chimie des Matériaux, Université Pierre et Marie Curie, Paris VI (2006), p. 327.

[24] D.M. Moore, R.C. Reynolds, X-Ray Diffraction and the Identification and Analysis of Clay Minerals, Oxford Univ. Press, Oxford, New York, 1997, p. 87.

[25] E. Ferrage, Chimie/Science des Matériaux, Université de Savoie-Université Joseph Fourier, Grenoble (2004), p. 326.

[26] A.K. Helmy, E.A. Ferreiro and S.G. de Bussetti, J. Colloid Interface Sci. 210 (1999), p. 167.

[27] F. Hetzel and H.E. Doner, Clays Clay Miner. 41 (1993), p. 453.

[28] L.J. Michot and F. Villiéras, Clay Miner. 37 (2002).

[29] F. Hetzel, D. Tessier, A.-M. Jaunet and H. Doner, Clays Clay Miner. 42 (1994), p. 242.

[30] J. Raynal and M. Jullien, Clay Sci. 12 (2006), p. 52.

[31] E. Rinnert, C. Carteret, B. Humbert, G. Fragneto-Cusani, J.D.F. Ramsay, A. Delville, J.L. Robert, I. Bihannic, M. Pelletier and L.J. Michot, J. Phys. Chem. 109 (2005). 


\section{Figures}

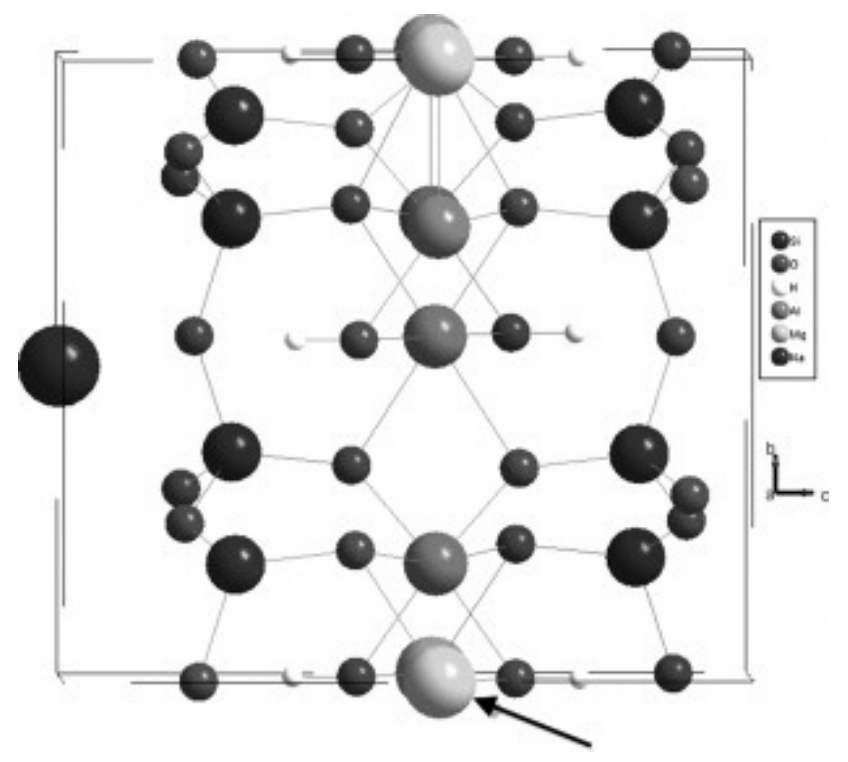

Fig. 1. Schematic representation of a unit cell of the Na montmorillonite, using Diamond software. The cell edge is drawn. We have given, for the sake of simplicity, a fixed position to the $\mathrm{Mg}$ substituting for an $\mathrm{Al}$ atom. This substitution is denoted by the arrow.

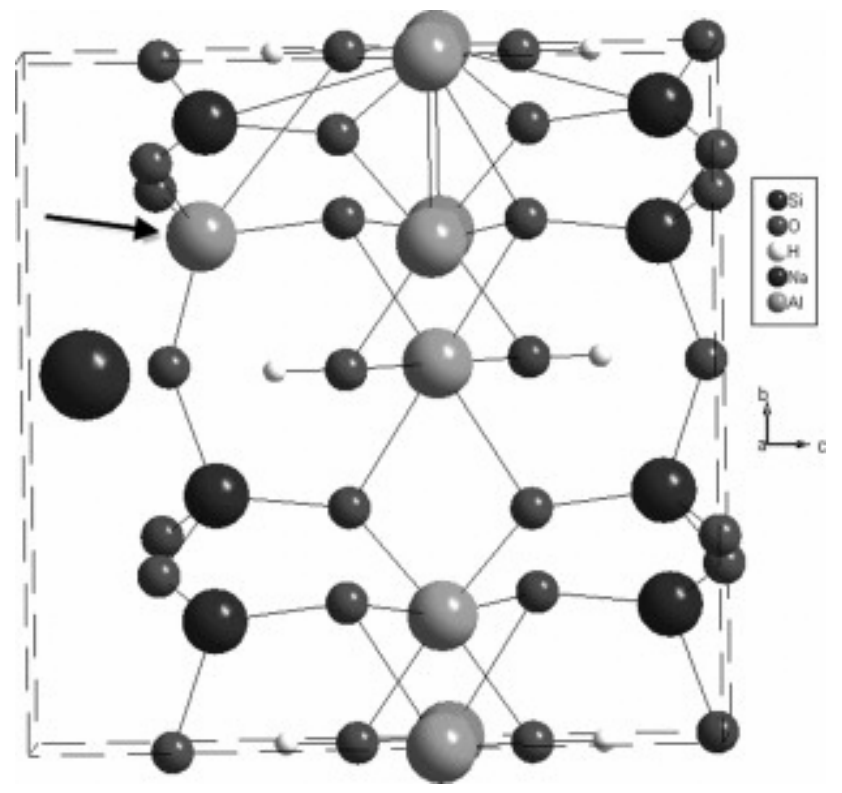

Fig. 2. Schematic representation of a unit cell of the beidellite, using Diamond software. The cell edge is drawn. We have given, for the sake of simplicity, a fixed position to the $\mathrm{Mg}$ substituting for an $\mathrm{Al}$ atom. This substitution is denoted by the arrow. 


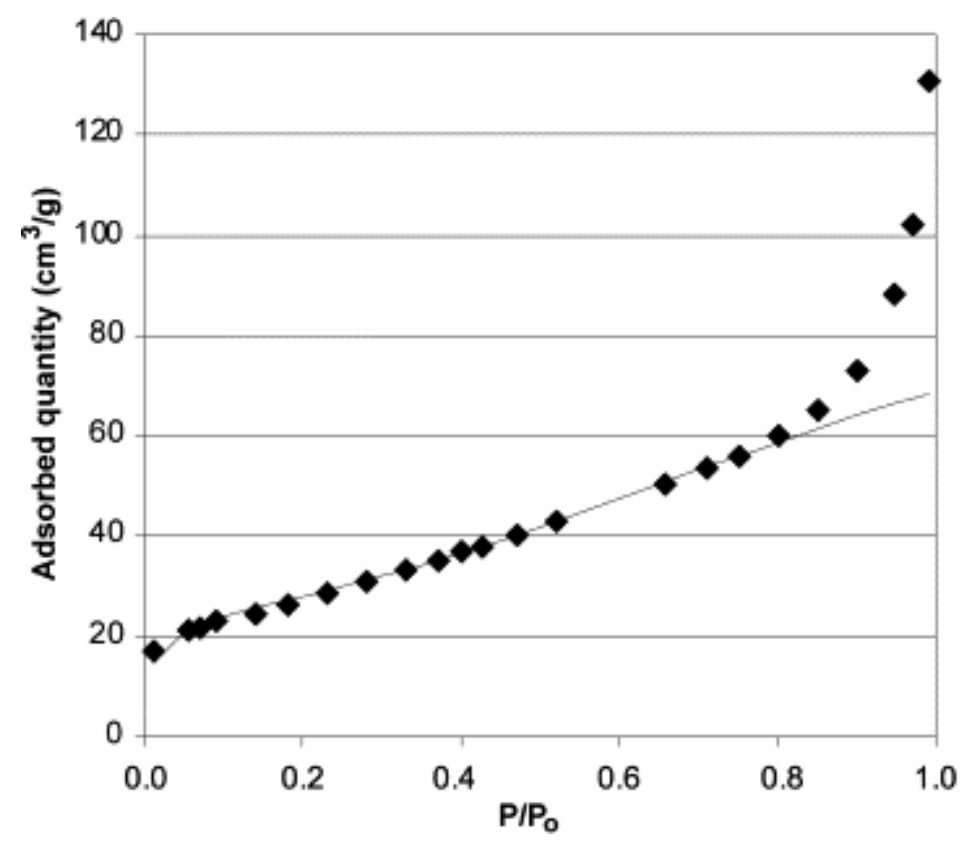

Fig. 3. Nitrogen adsorption isotherm on SB 303 at $77 \mathrm{~K}\left(\mathrm{~cm}^{3}\right.$ of vapor at S.T.P. per g of solid). Black diamonds: experimental data, black line: Lecloux-Pirard isotherm fitted from BET analysis. Parameters are $C=150 ; N=5.5$.

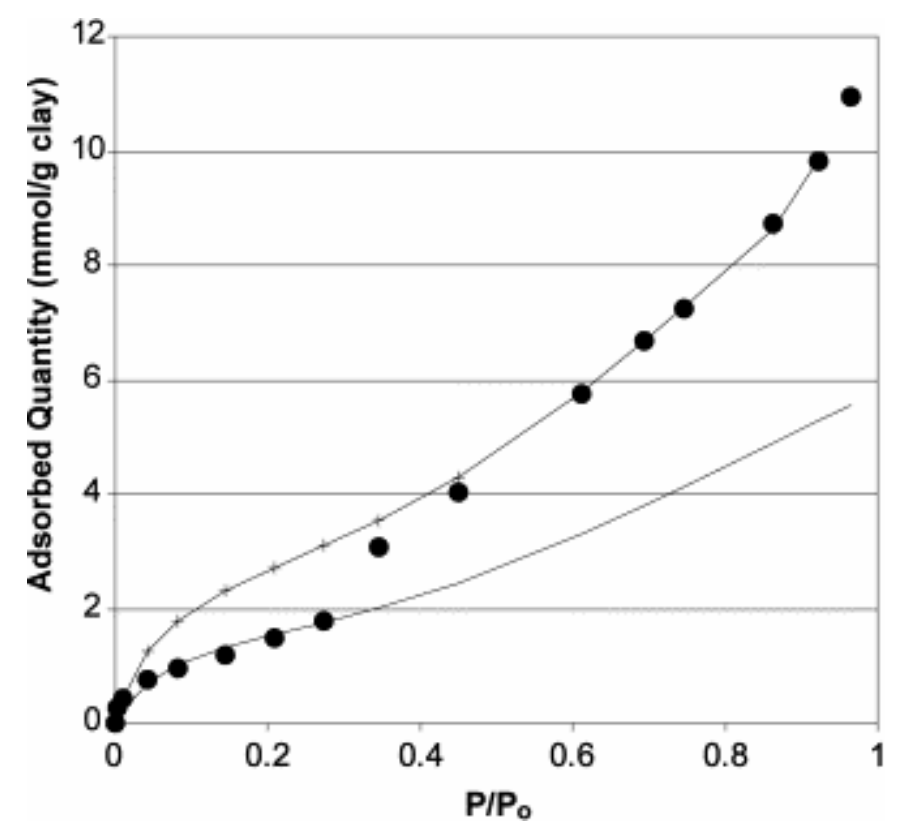

Fig. 4. Adsorption of water onto synthetic beidellite at 298 K. Dots: experimental data. Line and crosses $(+)$ line: Lecloux-Pirard isotherms (data corresponding to Table 2). 


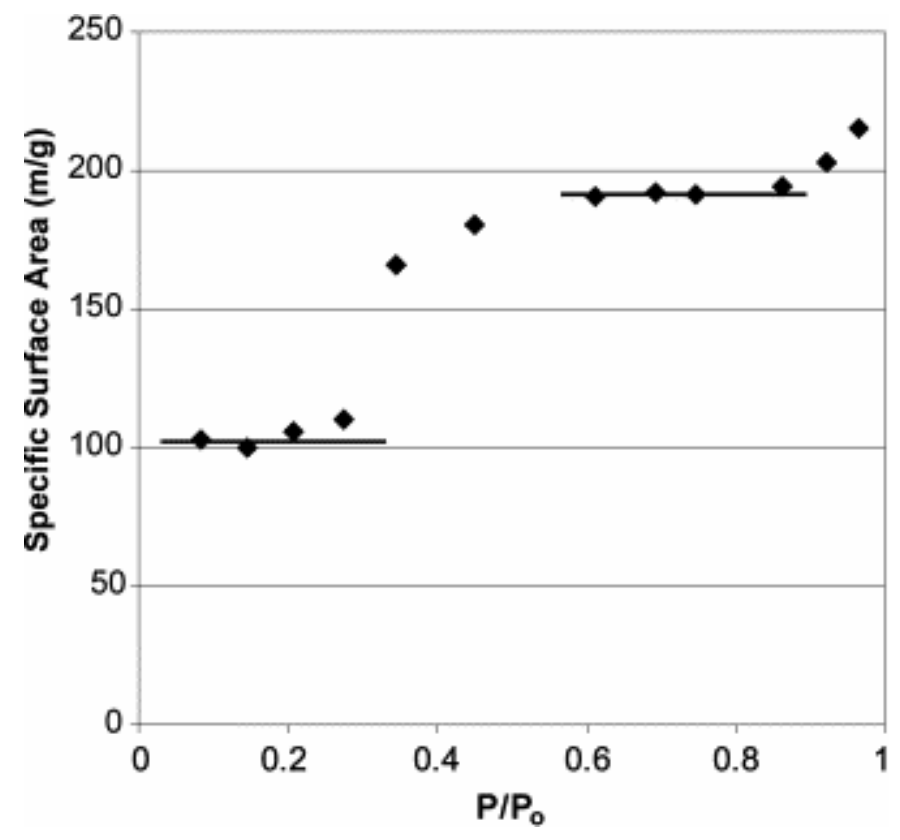

Fig. 5. Variation of the specific surface area of the synthetic beidellite deduced from analysis of the experimental isotherm (black diamonds). Lines are guides for the eyes.

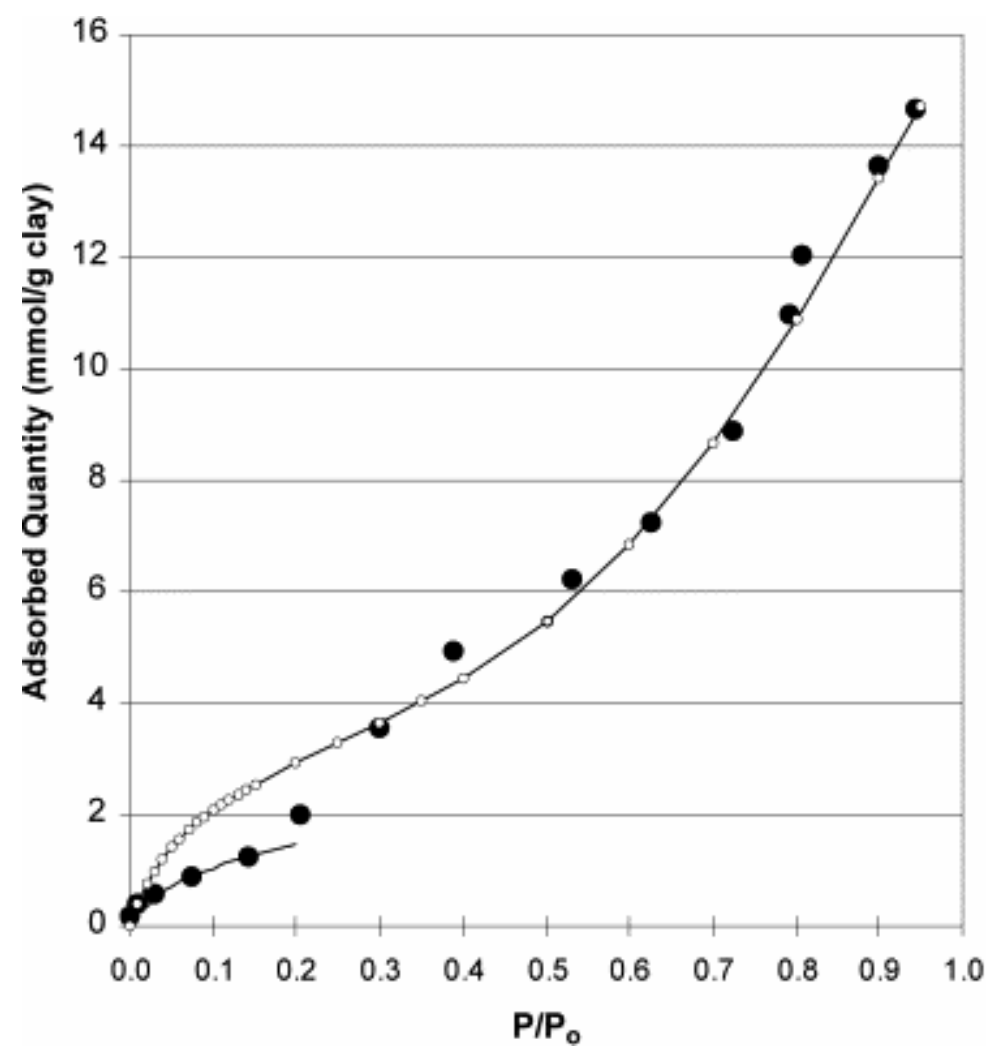

Fig. 6. Adsorption of water onto synthetic montmorillonite at 298 K. Dots: experimental data. Line and open dotted line: Lecloux-Pirard isotherms (data corresponding to Table 2). 


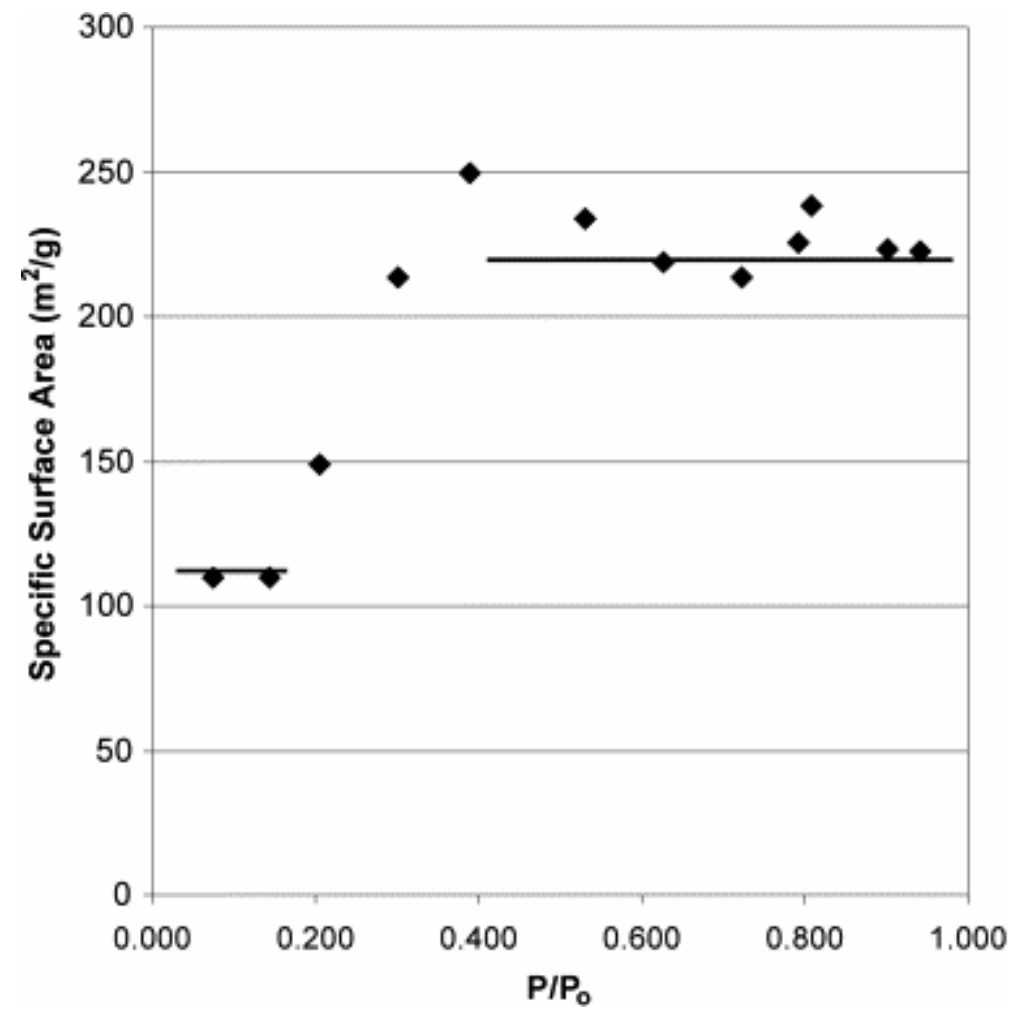

Fig. 7. Variation of the specific surface area of the synthetic montmorillonite deduced from analysis of the experimental isotherm (black diamonds). Lines are guides for the eyes.

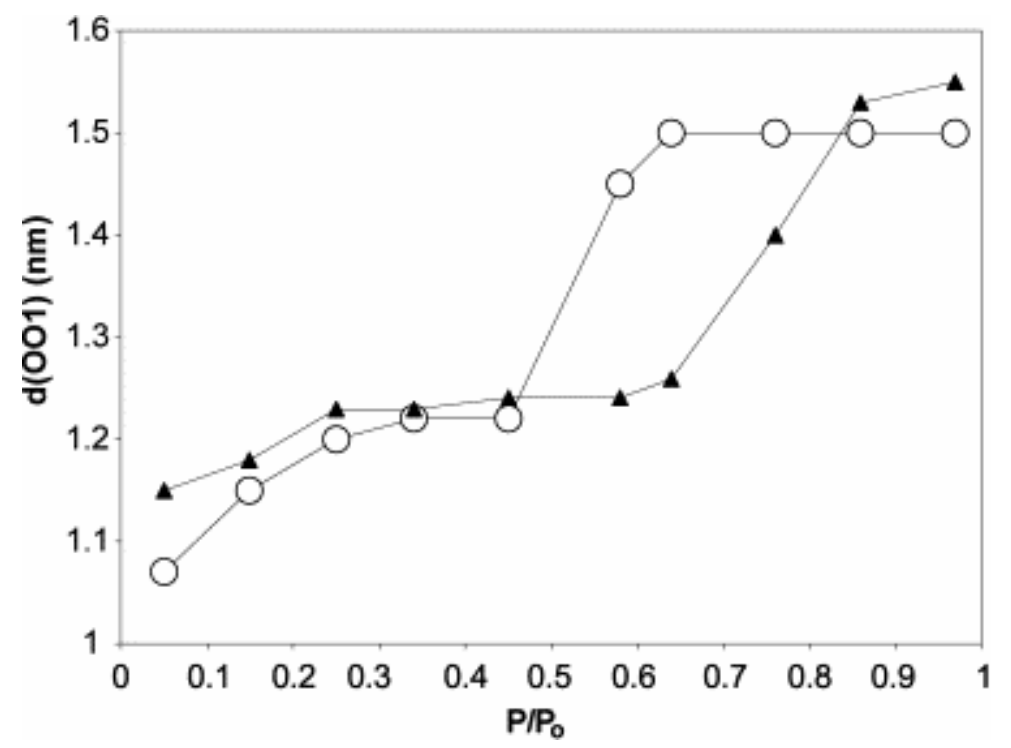

Fig. 8. Variation of the $d(001)$ line versus the partial pressure of water at ambient temperature. Open circles: montmorillonite; black triangles: beidellite. Lines are guides for the eyes. 


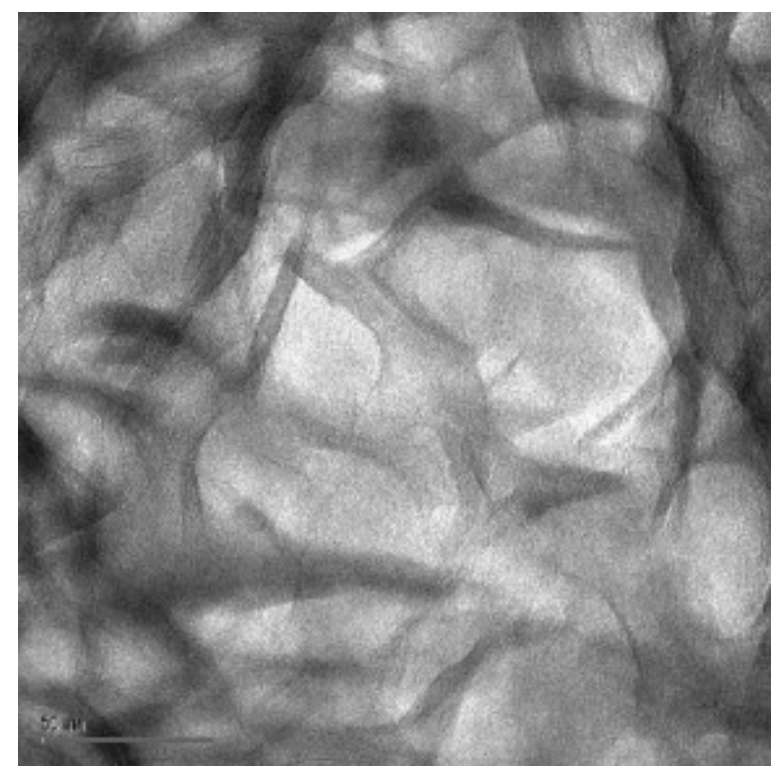

Fig. 9. TEM photographs of the montmorillonite. Black bar corresponds to $50 \mathrm{~nm}$.

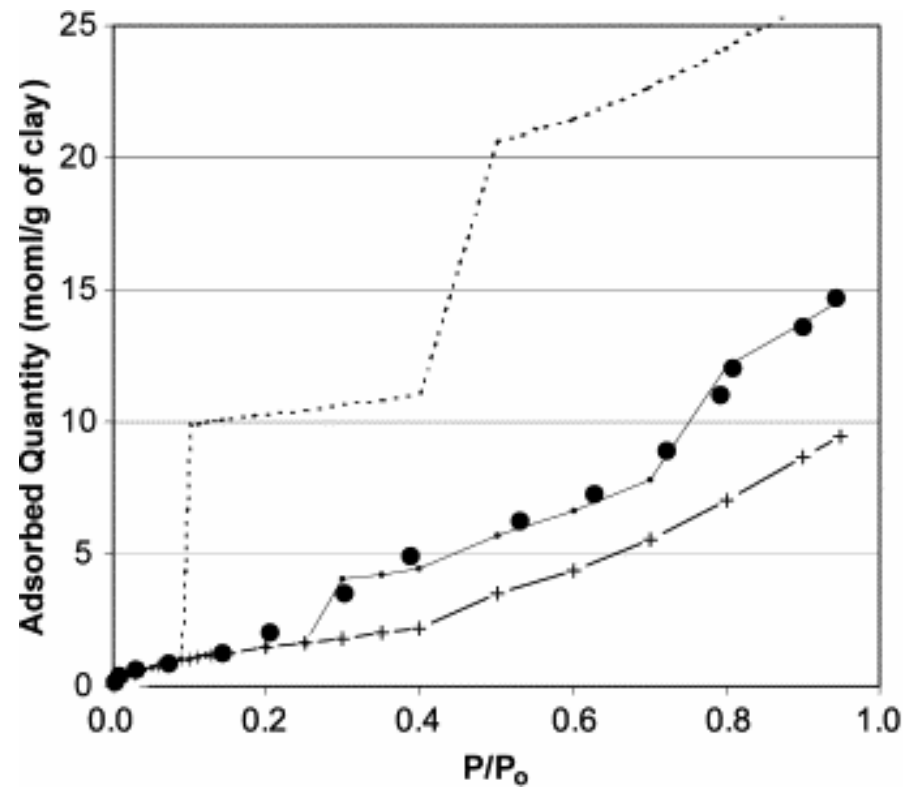

Fig. 10. Calculation of the various possible adsorbed quantities for montmorillonite. Dots: experimental data. Crossed line: Lecloux-Pirard isotherm taking into account the opening of the interlayer. Dotted line: full adsorption taking also into account the filling of the interlayer space (one-layer hydrate followed by two-layer hydrate). Full dotted line: simulation by the sum of the Lecloux-Pirard isotherm (same as the preceding) and a partial filling $(25 \%$ of the one-layer hydrate and $30 \%$ of the two-layer hydrate). This calculation corresponds to the montmorillonite X-ray picture. 


\section{Tables}

Table 1. : Chemical formulae per unit cell (from Refs. [2] and [3])

\begin{tabular}{|l|l|}
\hline Sample & Chemical formulae \\
\hline $\mathrm{SB} 1-350$ & $\mathrm{Na}_{0.76}\left(\mathrm{Al}_{4.00}\right)\left(\mathrm{Si}_{7.20} \mathrm{Al}_{0.80}\right) \mathrm{O}_{20} \mathrm{OH}_{4}$ \\
\hline $\mathrm{SM}_{0.33}-1200$ & $\mathrm{Na}_{0.68}\left(\mathrm{Al}_{3.32} \mathrm{Mg}_{0.72}\right)\left(\mathrm{Si}_{7.94} \mathrm{Al}_{0.06}\right) \mathrm{O}_{20} \mathrm{OH}_{4}$ \\
\hline
\end{tabular}

Table 2. : Specific surface areas and data issued from adsorption analysis deduced from nitrogen adsorption and water adsorption (at $\underline{P / P_{0}} \underline{=0.1}$ and 0.8 )

\begin{tabular}{|c|c|c|c|c|c|}
\hline Solid & $\begin{array}{l}\underline{A}_{S} \text { from } \mathrm{N}_{2} \\
\text { adsorption and } \\
\text { BET equation } \\
\left(\mathrm{m}^{2} / \mathrm{g}\right)\end{array}$ & $\begin{array}{l}\text { Water } \\
\text { adsorption: } \underline{A}_{s} \\
\text { at } \frac{P / P_{0}}{=0.1} \\
\left(\mathbf{m}^{2} / \mathbf{g}\right)\end{array}$ & $\begin{array}{l}\text { Water } \\
\text { adsorption: } \underline{A_{s}} \\
\text { at } \frac{P / P}{P}=0.8 \\
\left(\mathrm{~m}^{2} / \mathrm{g}\right)\end{array}$ & $\begin{array}{l}\text { Final number of } \\
\text { layers of water } \\
\text { (using the BET } \\
\text { definition of the } \\
\text { first monolayer) }\end{array}$ & $\begin{array}{l}\text { Constant } C \\
\text { for water } \\
\text { adsorption }\end{array}$ \\
\hline Synth. beidellite & 98 & 103 & 191 & +7 & 20 \\
\hline $\begin{array}{l}\text { Synth. } \\
\text { montmorillonite }\end{array}$ & 101 & 109 & 222 & +10 & 16 \\
\hline $\begin{array}{l}\text { Nat. } \\
\text { montmorillonite }\end{array}$ & 44 & 126 & 260 & +4.76 & 15 \\
\hline
\end{tabular}

Table 3. : Calculation of the adsorption ( $\mathrm{mmol} / \mathrm{g}$ of clay) onto the external surface and of the maximal adsorbed quantity possible inside the interlayer space. This calculation depends on the number of layers associated in a particle. The chosen numbers correspond to the montmorillonite case

\begin{tabular}{|l|l|l|l|l|l|l|l|}
\hline$\underline{\mathbf{P} / \mathbf{P}_{\mathbf{0}}}$ & $\begin{array}{l}\text { Number } \\
\text { of layers } \\
\text { along } \boldsymbol{c}-\end{array}$ & $\begin{array}{l}\text { Basal } \\
\text { axis }\end{array}$ & $\begin{array}{l}\text { Calculated } \\
\text { distance }\end{array}$ & $\begin{array}{l}\text { Calculated } \\
\text { internal } \\
\text { adsorption } \\
\text { adsorption } \\
\text { (one-layer } \\
\text { hydrate) }\end{array}$ & $\begin{array}{l}\text { Calculated } \\
\text { interlayer } \\
\text { adsorption } \\
\text { (two-layer } \\
\text { hydrate) }\end{array}$ & Sum & $\begin{array}{l}\text { Experimental value } \\
\text { (for synthetic } \\
\text { montmorillonite) }\end{array}$ \\
\hline 0.4 & 9 & 12.25 & 2.22 & 4.43 & & 6.65 & 5 \\
\hline 0.85 & 7 & 15 & 7.81 & & 17.11 & 24.92 & 12 \\
\hline
\end{tabular}

